\title{
Movement Patterns of Electric Cargo Bike Commuters - First Insights from Field Experiments and Trajectory Analyses
}

\author{
Andreas Keler ${ }^{\mathrm{a}, *}$, Lisa Kessler ${ }^{\mathrm{a}}$, Fabian Fehn ${ }^{\mathrm{a}}$, Klaus Bogenberger ${ }^{\mathrm{a}}$ \\ ${ }^{a}$ Chair of Traffic Engineering and Control, Technical University of Munich, andreas.keler@tum.de, lisa.kessler@tum.de, \\ fabian.fehn@tum.de, klaus.bogenberger@tum.de \\ * Corresponding author
}

\begin{abstract}
In addition to and parallel to the SERVUS project, the requirements for a new, agile, urban cargo bicycle with electric drive are identified through a targeted, scientific application potential analysis in the project "E-Cargo Bike Accompanying Research" described here. These findings are then implemented in the SERVUS project in an agile development and production process. Several prototypes are built in the process. The new e-cargo bicycles should be able to be used both privately and commercially. They will be presented to users for the first time at events (IAA 2021) and rated by them. In addition, the longer-term allocation of the bikes to selected users enables a cross-comparison with existing e-cargo bicycle models. Finally, the substitution potential of journeys in motorized individual transport is estimated and projected using the example of Munich. A key for gathering further information on the abilities of specific electric cargo bike types is tracking experiments with various sensor setups of which the first attempts are presented in this research. Additionally, and by enabling a certain spatial accuracy of gathered GNSS data, we are able to match selected maneuvers of these vehicle types to selected types of the Munich transportation infrastructure. Besides trajectory shapes of maneuvers, we are able to incorporate travel time and delay variations depending on investigation areas and times of the day at selected urban locations for every inspected maneuver (at for examples differing intersection geometries with and without traffic light signals). Another aspect is the presence of bicycle infrastructure and its relation to the option of using mixed traffic modes.
\end{abstract}

Keywords: Tracking Experiments, GNSS, Trajectory Analysis, Semantic Enrichment, Active Travel Modes, Transportation Infrastructure

\section{Introduction}

Electric cargo bicycles are a useful complement for urban courier and postal logistics and partially for private usage, as for example for parents transporting their children to kindergartens and schools. The latter comes as well with the problems arising from the extended sizes of these vehicles leaving more problems with parking but as well with maneuvering along bicycle infrastructure as the present bicycle infrastructure might not fully serve these bicycle types. Due to the widths and lengths of (electric) cargo bikes, their riders might tend to join mixed traffic mode on those lanes initially assigned for motorists. Depending on the average speeds and maneuvering abilities of every electric cargo bike type and user, the electric cargo cyclist might more or less appear as a moving obstacle for different road user types (motorist, cyclist and pedestrian).

The aim of the ongoing research project "E-Cargo Bike -Application Possibilities of Urban Electric Cargo Bicycles -- Accompanying Research", which is funded by the Bavarian Ministry of Economic Affairs, Regional Development and Energy, is the longer-term allocation of an innovative novel electric cargo bicycle to selected users to enable a cross-comparison with existing e-cargo bicycle models. The new e-cargo bicycles, of which several prototypes will be built in the process, should be able to be used both privately and commercially. They will be presented to users for the first time at events (IAA 2021) and rated by them. This means within this project we focus on (1) user studies with tracking experiments, and on (2) user surveys at public events. Based on the findings and analyses outcomes, we estimate the substitution potential of journeys in motorized individual transport and project it onto the example of Munich, Germany.

\section{State of the Art in Science and Technology}

Cargo bikes have a great, so far insufficiently exploited potential for private and commercial transport and can make a significant contribution to environmentally friendly mobility in urban areas. They are becoming increasingly important in urban transport, are being promoted both regionally and internationally, and are set to become an integral part of the transport turnaround (BMVI, 2019). Compared to motorized individual transport, the cargo bike combines many advantages, such as low acquisition and operating costs, locally emissionfree transport, higher driving flexibility, no registration requirement (Bodanksi and Cailliau 2020), as well as the use of the traffic area bike path, away from the public road. The market and acceptance for this type of bicycle are also increasing. According to estimates by the Zweiradindustrieverband, growth in 2019 in this segment was $+40 \%$ to a total market share of $1.76 \%$ of all bicycles sold in Germany. Willingness to buy cargo bikes among potential bike buyers increased by two percentage points in 2019 compared to 2017 (5\%). $20 \%$ of urban respondents who do not own a cargo bike could imagine to buy one 
(Sinus Institute 2019). The willingness of urban dwellers to acquire a cargo bike is thereby higher than in rural areas. However, so far only $3 \%$ of cyclists ride a cargo bike (study with $\mathrm{N}=2376$ ) or $2 \%$ of pedelec users $(\mathrm{N}=344)$. Most scientific studies and pilot projects are therefore limited to the commercial and logistical usage of cargo bikes, e.g., in the form of courier services. A study by DLR, for example, shows that the innovation and substitution potential of e-load bikes for courier service use is very high and could thus replace one fifth of the internal combustion engine mileage in cities (Gruber 2015).

Reasons cited against cargo bikes in the private sector include lack of need (due to car ownership), unhandiness, bulkiness, and the inability to transport people (Sinus Institute 2019). Also, in several studies with test persons, the insufficient width of bicycle paths, obstacles on bicycle paths (such as parked cars), and a lack of suitable parking facilities are mentioned, which often leads to a renunciation of trips with this means of transport (Sinus Institute 2019, Becker and Rudolf 2018, Anderluh et al. 2018). A study in the Americas also cites poor parking in densely populated areas and the price of the bikes as major barriers to be purchased by families (Thomas 2016). The heavy weight of cargo bikes also reduces the range that electric propulsion can achieve (Bodanksi and Cailliau 2020). The relatively large bulkiness, length, and greater weight, coupled with more difficult handling in intersection and evasive situations and the inadequate bicycle infrastructure in cities offers a great potential for more innovative cargo bike design. Important here is not only improved riding dynamics, but also the potential of the cargo area, as test subjects mainly transport food, beverage crates, goods, furniture, or even children with the cargo bikes (Rudolf and Becker 2018).

Cargo bikes are subsidized and promoted by the federal and state governments, but also specifically by cities. At the state level, the usage of e-load bikes is mainly promoted in the commercial sector, associations, nonprofit organizations, and businesses. Cities often also target private funding: for example, the cities of Munich and Mannheim subsidize e-load bikes with $25 \%$ of the purchase price up to $1000 €$, and in Stuttgart families and single parents receive funding of up to $1500 €$. With the \#moinzukunft program, Hamburg takes a pioneering role and subsidizes electrically as well as manually operated cargo bikes with $33 \%$ of the purchase price in both the commercial and private sectors (GreenBike Blog 2020).

The Chair of Traffic Engineering and Control at the Technical University of Munich can already look back on numerous experiences in the field of surveys in the topic area of traffic and mobility, such as from the projects on the truck parking guidance system, the Digital Test Field A9 of the BMVI (BMVI 2020) or 360-degree parking (Margreiter et al. 2017). In addition, extensive knowledge is available in the field of traffic data analysis and statistical projection models. For example, a proprietary multi-stage model has been developed to determine the demand for public charging stations (Niels et al. 2020). A so-called "system dynamics model" was used to estimate the market for robotic shuttle vehicles in Germany (Kaltenhäuser et al. 2020).

In addition, this chair provided scientific support for a novel inner-city logistics concept with microdeposits and (e-)cargo bikes together with UPS. Optimal micro depot locations and routes were identified, taking into account the capacities of the cargo bikes (Niels et al. 2018).

\section{Experimental Setup}

Figure 1 shows the three different electric cargo bicycles tested within this project, where the ones in Figures 1a and $1 \mathrm{~b}$ are two-wheelers, the one in Figure $1 \mathrm{c} / \mathrm{d}$ is a threewheeler or trike. All of these types have the cargo area in the front of the steering wheel. The innovative electric cargo bicycle will be tested in October 2021 (not yet available).

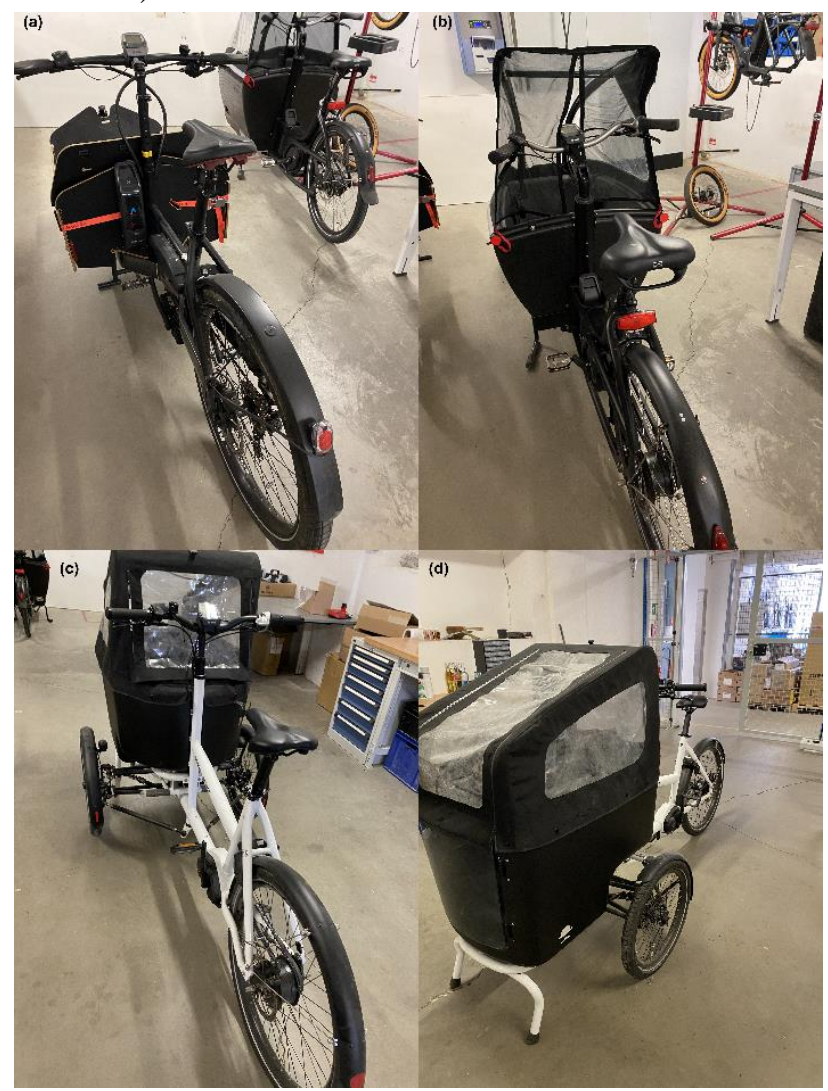

Figure 1. Depiction of the currently-tested electric cargo bicycles within the user studies of the project with (a) Riese\&Müller Packster 70, (b) Urban Arrow Family and (c) Butchers \& Bicycles MK1-E TOURING from the back and (d) from the front.

The initial experimental setup consists of testing phases of respectively 3 weeks. Afterwards, we exchange the bicycles on a date, where the users have the chance to do a first test ride with another bicycle. Our test subjects perform trips with one of the 3 (later 4) electric cargo bikes with different purposes. Furthermore, they commute as this is part of the key requirements for our trajectory analysis methodology. Based on user studies with conducted tracking experiments, where electric cargo bike user test subjects record every trip and fixate its purpose and properties supported by an online questionnaire 
similar to those of a travel diary, we quantify the specific movement patterns based on GNSS recording, enabled, after pretesting different applications, with the smartphone application 'Komoot'. Additionally, there are two other questionnaire types: one for the initial survey on the test subject's cycling style and one after handling one electric cargo bicycle to the next test subject on a general assessment of the respective bicycle.

\section{First Trajectory Analyses Outcomes}

The recorded trajectories from one of the test subjects are depicted in Figure 2. Different colors refer to different trip recordings. The longest route comprises nearly $60 \mathrm{~km}$ without in-between charges. In our surveys, people stated a range anxiety in connection with probably frequent charging actions. One important outcome so far is the large range without any charges while riding such a bicycle.

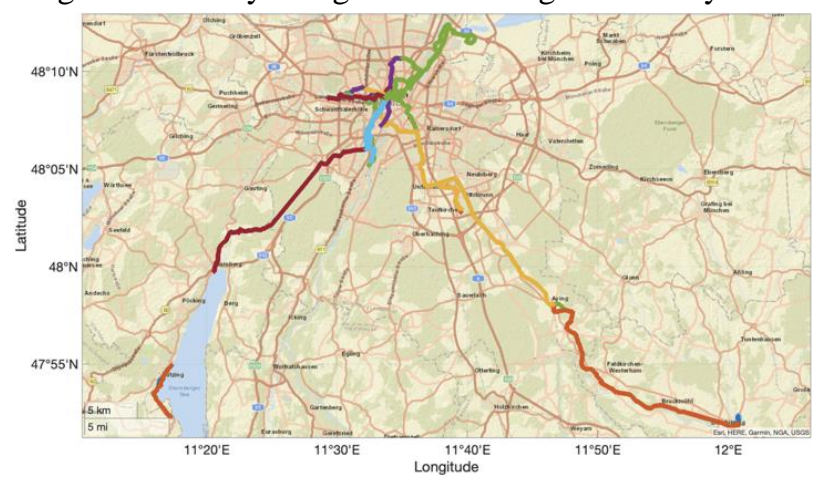

Figure 2. Test subject's bicycle routes in the Greater Munich area in a two weeks trial phase.

Restricted to urban trips, Figure 3 shows a conglomeration of trips centering the main campus of the Technical University. Numerous rides touch identical road stretches and enable to compare single trips regarding different research objectives.

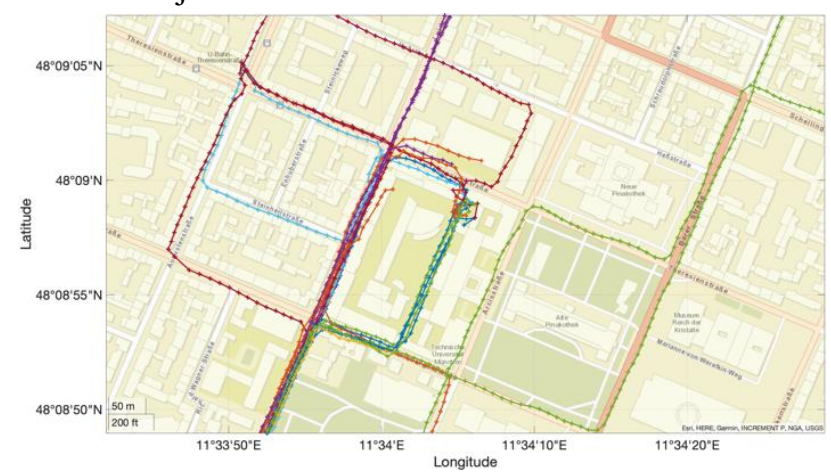

Figure 3. Test subject's bicycle routes in Munich city center.

One research objective is the investigation of route deviations while comparing GNSS tracks from our e-cargo bike with multiple different types of bikes, such as a traditional (non-electric, non-cargo) bicycle, a conventional e-bike, various forms of children's transport systems (e.g., trailers or bike seats), and various forms of a cargo box (e.g., trailers).

As one of the test subjects for the experiments started tracking personal daily commuter routes with a non- electric non-cargo bicycle (specified at a later stage of the project, e.g., together with the questionnaire outcomes), we started to design a methodology for obtaining the movements pattern differences of two different vehicles. Figure 4 pictures the raw trajectories of the movements with a non-electric bicycle (green) and with the Riese\&Müller Packster 70 bicycle (red) of one of the test subjects for a cut-out of the commuter investigation area in Munich, Germany. It is obtainable that at selected parts, the route alters whether based on traffic conditions or (transport-)infrastructural abilities. Based on additional OpenStreetMap extracts of the road segment representations, we identify (and extract) those vertices (from road segment polylines) where road types change within our trajectory analyses. Additionally, we relate the raw trajectories with POIs and further inspect the areas around the road intersections, where the densities of extracted road segment vertices are higher due to the higher curvatures and the partially-complex relation to sidewalks is obtainable.

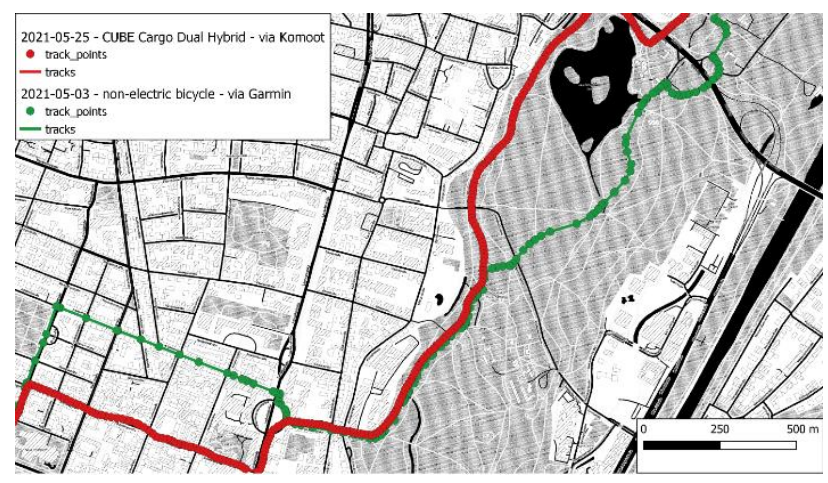

Figure 4. Map view with a raw bicycle trajectory visualization of a (green) non-electric bicycle (as of May 3, 2021), and a (red) electric cargo bike, in the city center of Munich.

\section{First Interpretation Attempts and Outlook}

Our first assumption is that sidewalks and other pedestrian transport infrastructure have an important influence on the movement patterns of cyclists and even more of electric cargo bike users.

Despite these first methodological approaches, we face general dissatisfaction by selected test subjects, mainly due to the fact that it is difficult to maneuver these heavy and long vehicles as well as park them in a suitable urban area. Moreover, selected test subjects indicated to perceive themselves, when riding the electric cargo bikes on important connection cycle ways connecting the suburbs with Munich, as obstacles for other cyclists. The latter comes together with the enlarged widths of electric cargo bikes compared to other bicycle types.

In the following steps within the project, we want to continue the experiments until the end of 2022 and aim to establish a trajectory data base with gathered semantic information depicting a whole variation of cargo bicycle movement patterns, which would serve us to quantify concerns and difficulties of using these vehicle types in densely-built urban environments. By finding and identifying the issues based on trajectory analyses and qualitative data from the questionnaire, we focus on 
identifying the substitution potentials, especially in relation to motorists, the currently missing infrastructural elements in relation to the current bicycle infrastructure and its usage by cyclists. Moreover, we want to point out the benefits of electric cargo bicycles for our current urban environments.

Additionally, we currently plan to obtain smartphones with LiDAR sensors mounted to the steering wheel or helmet to gather point clouds representing parking conditions or the conditions of the transport infrastructure (for validating the trajectory analysis outcomes.

\section{Acknowledgements}

We want to thank our project partner within the publiclyfunded project SERVUS, the Bavarian company CUBE (Pending System GmbH \& Co. KG) for lending us the test electric cargo bicycles and supporting us with valuable information on various technical details.

\section{References}

Anderluh, A., Hemmelmayr, V. and Walkolbinger, T. (2018). Einsatz von Lastenfahrrädern zur innerstädtischen Güterlieferung - Ein Städtevergleich und Best Practice Empfehlungen für die Stadt Wien. Wirtschaftsuniversität Wien.

Becker, S. and Clemens, R. (2018). Exploring the potential of free cargo-bikesharing for sustainable mobility. Gaiaecological perspectives for science and society $27.1,156-$ 164.

BMVI (2019). Nationaler Radverkehrskongress in Dresden. Scheuer: Ich werde den Radverkehr deutlich stärken.

https://www.bmvi.de/SharedDocs/DE/Pressemitteilungen/201 9/040-scheuer-radverkehrskongress.html

BMVI (2020). Digitales Testfeld Autobahn. https://www.bast.de/BASt_2017/DE/Verkehrstechnik/Fachthe men/V5-digitales-Testfeld.html?nn=1497198

GreenBike Blog (2020). Lastenrad-Förderung: Übersicht der Kaufprämien. https://www.greenbikeshop.de/blog/lastenrad-foerderung-uebersicht-der-

kaufpraemien

Gruber, J. (2015). Ich ersetze ein Auto: ElektroLastenräder für den klimafreundlichen Einsatz im Kuriermarkt. Vorhaben 03KSF029 der Nationalen Klimaschutzinitiative des BMUB. Projektbericht.

Kaltenhäuser, B., Werdich, K., Dandl, F. and Bogenberger, K. (2020). Market development of autonomous driving in Germany. Transportation Research Part A: Policy and Practice 132, 882-910.

Margreiter, M., Orfanou, F., Mayer, P., Alpas, M. and Vlahogianni, E. (2017). Driver's Willingness to Use Parking Assistance Tools and their Expectations: A Case Study for the Cities of Munich and Athens. 8th International Congress on Transportation Research.

Niels, T., Hof, M.T. and Bogenberger, K. (2018). Design and operation of an urban electric courier cargo bike system. 201821 st International Conference on Intelligent Transportation Systems (ITSC), 2531-2537.
Niels, T., Bogenberger, K., Gerstenberger, M. and Hessel, C. (2020). Modellbasiertes Vorgehen zur Ermittlung von Standorten öffentlicher Ladeinfrastruktur - Methodik und Anwendung am Fallbeispiel Landkreis München. Straßenverkehrstechnik, November 2020.

Thomas, A. (2016). A More Sustainable Minivan? An Exploratory Study of Electric Bicycle Use by San Francisco Bay Area Families. UC Davis: National Center for Sustainable Transportation. https://escholarship.org/uc/item/6g79m3xx

Sinus-Institut (2019). Fahrrad-Monitor Deutschland 2019. Ergebnisse einer repräsentativen Online-Befragung. https://www.bmvi.de/SharedDocs/DE/Anlage/K/fahrradmonit or-2019-ergebnisse.pdf?__blob=publicationFile 